Whitehouse (also for Whitmore, Great Britain) and Wilten (also for Wijvekate, The Netherlands) described the methods used at their institutes for evaluating the malting quality. The practical uses of these micro-malting tests in genetic experiments and breeding were discussed. Raw (Australia) reviewed the breeding for malting barley in southern Australia; Lekeš (Czechoslovakia) presented a similar review of the problems in his country.

Finally, Gotoh (Japan) described phenotypic expressivity of various genotypes and the use of differences of expressivity in various environments in order to arrive at an efficient selection. Finlay (Australia) presented an investigation of the classification of varieties as to their adaptability to environments. The evaluation of this investigation for selection was discussed.

The closing session dealt with three main subjects. The first concerned the election of a Permanent Barley Committee. This Committee, with Dr. G. A. Wiebe (United States) as president and Dr. R. A. Nilan (United States) as secretary, will have the task of organizing the next barley symposium and of co-ordinating barley research. It was difficult to decide in advance the full task of this Committee; its activities will be made more precise in the near future.
Two resolutions were presented and discussed which had been prepared in small discussion groups of specialists. The first dealt with the "Origin and Phylogeny of Barley". It is proposed to undertake joint investigations and co-ordinate the work in this field: the organization of international expeditions was specially mentioned. The second resolution dealt with "Procedures for the Nomenclature and Handling of Genetic Stocks", where specialists would like to see closer co-operation. A motion was presented concerning the appointment of co-ordinators for maintenance and nomenclature of genetic stocks (for example, genetic markers, translocations, trisomics, resistant lines, autotetraploids, etc.). The stocks will be available to all investigators and any new stock will be sent to collaborators, together with complete information on this stock.

Finally, it was announced that the Proceedings of this Symposium, containing the full text of all papers, discussions and resolutions, would be published some time in 1964 by the Centre for Agricultural Publications and Documentation (PUDOC), Wageningen.

The Symposium was a great success; the organizing committee, with Dr. Lamberts as secretary, earned the appreciation of all participants.

W. LANGE:

\title{
SAFETY AND RELIABILITY OF SEA AND AIR TRANSPORT
}

\begin{abstract}
A CONFERENCE entitled "The Safety and Reliability of Sea and Air Transport" was held by the British, French and German Institutes of Navigation in the Congress Hall at Eastbourne on May 12, and was attended by some four hundred delegates.

In his presidential address, Dr. G. E. R. Deacon, president of the Institute of Navigation in London and director of the National Institute of Oceanography, Wormley, pointed out that such conferences offered opportunities for specialists from all sides, meeting on level terms, to identify and appraise a problem and research area of wide significance. The results of previous work were beginning to bear fruit. After the last tripartite conference, the Dover Strait Working Group had been formed to look into the desirability of routing at sea in general, with particular reference to the Dover Strait. The Group's recommendations had received overwhelming support from master mariners, and had recently been accepted by the Maritime Safety Committee of the Intergovernmental Maritime Consultative Organization, and the Maritime Safety Committee was proposing that as early as possible Governments should be asked to advise their ships to follow the routes suggested by the Working Group.
\end{abstract}

This was quite speedy action compared with the start of the North Atlantic routes, and Dr. Deacon commented that a recent biography of Matthew Fontaine Maury, U.S. Navy, was a good reminder of their early history. After 300 lives had been lost in a collision between the U.S. steamer Arctic and the French steamer Vesta in thick fog in 1854, a prominent shipowner in Boston had consulted Maury on the practicability of defining lanes in which steamers would be required to travel. This was soon followed by a formal request from a group of underwriters, shipowners and merchants, and Maury drew up a scheme which was published in 1855. Many steamships used the scheme and at least one company advertised that travellers could trust in the safety of its ships because they followed Mrury's steam lanes. When the Ville de Havre was lost in 1874 The Times had commented that "If she had followed Maury's steam lanes this terrible loss of life and ship would have been avoided". It was not until 1889 that a marine conference at Washington considered the question of sea lanes, and not until 1898 that a plan was agreed upon.
The findings of the present conference, Dr. Deacon pointed out, had no official authority, but the considered view of a representative group of specialists, speaking rather more freely in Eastbourne than they might in their own capital cities, must be to everyone's advantage. The programme of the conference covered a wide range of subjects, but with many a common theme. When two sailors debated a difficult point it might well be that an airman would supply the answer, and the seamen would no doubt profit from seeing some of their rather unyielding problems translated into the more rarefied environment of high-speed flight. In many branches of science and technology the increasing necessity for better and more economical performance meant that it was necessary to concentrate on the second-order terms-the sort of things that the conference had felt able to neglect in its first and very serviceable approach. In all-weather landing, for example, the human pilot must to an increasing extent be assisted by automatic techniques. The same was true for the special problems of supersonic flight where the information that instruments provide must be extensively 'processed' if the human pilot was to act on it fast enough. In the sea supplementary methods and refined techniques could be devised, which, although at first appearing to be too novel or elaborate for ordinary use, would permit advances to be made with the times as safely and reliably as all forms of transport.

The 'business' part of the conference was divided into thirteen consecutive sessions which dealt with many diverse aspects of navigation. Papers presented included insurance and the collision problem at sea; recommended routes in congested areas; the separation of aircraft and regulation of air traffic; all-weather landing; radar and the human operator; marine radar development; bridge design and human factors; shipborne communications and nav-aids; the regularity of traffic flow on inland waterways; meteorological factors in supersonic flight, etc. Contributors, while coming mainly from Britain, France and Germany, also included representatives from the United States, the Netherlands and Italy.

At the end of the conference there was general agree. ment that immediate measures should be taken to enable ships to navigate through heavily congested areas with more efficiency and a higher degree of safety. The three Institutes, the Institute of Navigation, Institut Français 
de Navigation and Deutsche Gesellschaft für Ortung und Navigation, agreed to set up a working group to determine and propose solutions for the areas in which the problem is most acute. The working group would comprise the representatives of shipping interests as well as experts from the various organizations which would have the technical responsibility for establishing the routes. In addition to making recommendations for the separation of traffic the group would consider the navigational aids which might be required.

Concerning air travel the discussion on supersonic transport indicated that a deeper investigation of the environment and its influence on the specification of the navigation system was necessary. The conference agreed that here the Institutes could perhaps make a unique contribution by clarifying the governing parameters and co-ordinating the various investigations that had so far been made. The three Institutes agreed to form an international working group to investigate the whole problem.

Further information concerning the conference can be obtained from Mr. M. W. Richey, executive secretary, the Institute of Navigation, at the Royal Geographical Society, 1 Kensington Gore, London, S.W.7.

\section{THE DIELECTRICS EVAPORATION GROUP}

$\mathrm{T}$ HE Dielectrics Evaporation Group was formed some five years ago under tho auspices of the Ministry of Aviation to promote the interchange of information between active workers in the field of evaporated thin dieleatric films and relevant subjects such as formation and properties of the metal electrodes.

Meetings are held every six months at some centre of research at which a number of informal papers dealing with the most recent research topics are delivered. These are reported in the form of notes on the meetings which are duplicated and distributed to all scientists with a genuine interest in the subject. Attendance at the meetings is by invitation and is restricted to active workers capable of making a significant contribution.

The Group is now under the patronage of the Joint British Council for Vacuum Studies and under the chairmanship of Mr. L. Holland (Edwards High Vacuum, Ltd.).

The tenth meeting of the Dielectrics Evaporation Group was held on March 25 at the Plessey Research Laboratories, Caswell. The following papers were read: "A Survey of the Resistive and Conductive Properties of Thin Metal Films", by Mr. J. Bennett (British Scientific Instrument Research Association); "The Mechanism of Conduction in Thin Films", by Dr. R. Hill (Electrical Research Association); "Structure Studies on NickelChromium Films", by Mr. H. Blackburn (Plessey Research Laboratories, Caswell); "The Quartz Crystal Rate-Meter", by Mr. H. Bath (Edwards Hi-Vacuum); "Studies of Rate Controlled Growth inside the Electron Microscope", by Messrs. D. J. Stirland, D. Carpenter and D. Dobbs (Plessey Research Laboratories, Caswell); "Studies of Thin Film Active Devices", by Mr. J. Acton (Plessey Research Laboratories, Caswell); "Vapour Phase Deposition of Thin Films", by Mr. B. A. Joyce (Plessey Research Laboratories, Caswell); "Deposition of Germanium Films", by Dr. J. C. Courvoisier (Battelle Research Institute, Geneva); "Differences in Growth Characteristics on Air and Vacuum Cleaved Substrate Surfaces", by Dr. O. S. Heavens (Royal Holloway College); "The Scanning Electron Microscope as a Means of Surface Study", by Mr. A. N. Broers (Department of Electrical Engineering, University of Cambridge).

From these papers some points emerged as worthy of special notice.

The conduction processes in very thin metal films are not yet fully understood. Such films usually consist of incompletely aggregated island structures on an insulating substrate. Conduction must therefore consist of the passage of electrons from island to island either directly or by means of the substrate. Dr. Hill considered that the former process may be discounted as leading to unacceptable values of resistance and temperature coefficient. He preferred the mechanism based on the passage of electrons to unoccupied levels in the macroscopically amorphous substrate and the ejection of equivalent electrons from the substrate into other such metal islands at a lower potential. Such a view could be consistent with Fröhlich's ideas on the existence of localized band structures in glassy materials. The small energy gaps would be overcome by the effects of the space charge developed. Results obtained by rough calculation were in reasonable agreement with experimental results for gold films on glass substrates, for which the island structure has been determined by electron microseopy.

Such an island structure had been observed by $\mathbf{M r}$. Blackburn, who had been studying the stability of evaporated nickel-chromium alloy resistors. It consisted of metal islands embedded in a glassy medium thought to be chromic oxide. Dr. Hill's proposed conduction mechanism could here well apply.

The processes of nucleation and growth (leading eventually to the island structure) depend critically on substrate conditions and residual atmosphere. Dr. Heavens showed that single crystal substrates freshly cleaved give very different results according to whether this has been done in air or in a good vacuum. The characteristic cleavage stop decoration observed for air cleaved substrates gave way to a random distribution of nucleation sites. The coalescence of these nuclei gave evidence of a high degree of orientation at much lower temperatures than is ordinarily the case. These effects were observed when the rate of arrival of metal atoms was at least comparable with that of the residual gas molecules (pressure approximately $2 \times 10^{-7} \mathrm{~mm}$ mercury).

Similar effects had been observed in the preparation of epitactic films of germanium by M. Courvoisier, using a poor vacuum, but depositing at a very high rate on a substrate heated almost to its melting point.

Nucleation processes very similar to those observed in vacuum deposition were described by Mr. Joyce for the vapour phase deposition of silicon from organic compounds.

The scanning electron microscope, with its large depth of focus and small electron spot size $(\sim 100 \AA)$, is emerging as a powerful tool for the study of surfaces. Mr. Broers described its use in combination with controlled ionbombardment etching for investigating such structures as thermally grown oxide films on iron, to which normal electron microscopy could not readily be applied. The depth of progressive etching of the surface can be controlled $( \pm 100 \AA)$ so that examination of the various layers can then be carried out with the electron probe. (Secondary emission during the ion bombardment makes it necessary to interrupt the etching during the electron scan.) The possible applications of this technique to thin films are clear. Such a process can be applied to the investigations of $p$ or $n$ conductivity in semiconductors, which emit secondary electrons of slightly different energies, although resolution may not be so high.

It is hoped the next meeting of the Group will be held some time in October.

J. R. BALMER

J. H. Brude 